\title{
Soils Developed from Dolomitic Shale in the Yichang Area, China and Adsorption Characteristics for Phenol
}

\author{
Mei Zou1,2,3, Liangcheng Xie1,2,3, Yan Liư4, Fujia Guan5, Chao Han4, Kangle Ding1,2,3* \\ ${ }^{1}$ Key Laboratory of Exploration Technologies for Oil and Gas Resources, Ministry of Education, Yangtze University, Jingzhou, \\ China \\ ${ }^{2}$ Shandong Provincial Key Laboratory of Depositional Mineralization \& Sedimentary Mineral, Shandong University of Science and \\ Technology, Qingdao, China \\ ${ }^{3}$ College of Chemistry and Environmental Engineering, Yangtze University, Jingzhou, China \\ ${ }^{4}$ College of Resources and Environment, Yangtze University, Wuhan Campus, Wuhan, China \\ ${ }^{5}$ College of Petroleum Engineering, Yangtze University, Wuhan Campus, Wuhan, China \\ Email: ^dingkl@yangtzeu.edu.cn
}

How to cite this paper: Zou, M., Xie, L.C., Liu, Y., Guan, F.J., Han, C. and Ding, K.L. (2020) Soils Developed from Dolomitic Shale in the Yichang Area, China and Adsorption Characteristics for Phenol. Open Journal of Yangtze Gas and Oil, 5, 145-164. https://doi.org/10.4236/ojogas.2020.54012

Received: June 23, 2020

Accepted: July 31, 2020

Published: August 3, 2020

Copyright $\odot 2020$ by author(s) and Scientific Research Publishing Inc. This work is licensed under the Creative Commons Attribution International License (CC BY 4.0).

http://creativecommons.org/licenses/by/4.0/ (c) (i) Open Access

\begin{abstract}
Recently, the problem of phenolic organics pollution has become increasingly serious. More and more strategies have been developed to remove phenolic organics from water, including oxidation, adsorption, chemical precipitation, etc. Among them, adsorption technology has attracted great attention due to its advantages of high efficiency, simplicity and easy operation. In this study, the natural shale soil without any modification was directly used as adsorbent to remove phenol from aqueous solutions. The shale soil samples were characterized by scanning electron microscope (SEM), X-ray diffraction (XRD), Fourier transform infrared spectroscopy (FT-IR) and nitrogen adsorption-desorption isotherms. Detailed kinetics and isotherm studies of phenol adsorption onto shale were investigated. According to the results of the orthogonal test, the influence degree of the four factors on the removal of phenol by soil samples was operating temperature $>$ adsorbent dosage $>$ contact time $>\mathrm{pH}$. The adsorption kinetics of phenols by the soil corresponded with the pseudo-second-order kinetic model. Thermodynamic studies indicated that Freundlich adsorption isotherm model could better describe phenol removal characteristics than Langmuir adsorption isotherm model. And the maximum adsorption capacity was found to be $9.68 \mathrm{mg} / \mathrm{g}$ for phenol. It is concluded that shale soil without any modification or activated methods could be employed as a low-cost alternative adsorbent for wastewater treatment.
\end{abstract}

\section{Keywords}

Shale, Soil, Phenol, Adsorption, Kinetics, Isotherm Model 


\section{Introduction}

Phenol, also known as carbolic acid, is a common contaminant in the chemical industrial wastewater. As a weakly ionizable aromatic organic compound, phenol is notorious for its acute toxicity on aquatic organisms [1], potential cancerogen, mutagenicity and teratogenicity on human beings [2] [3], as well as refractory biodegradation with respect to wastewater treatments [4]. The discharge of phenolic effluents into water bodies without a prior satisfactory treatment would pose significant public health risk as well as serious threat to the aquatic ecosystems. In China, the Ministry of Ecology and Environment (MEE) has set a discharge standard of less than $0.3 \mathrm{ppm}$ of phenol in the effluents from municipal wastewater treatment plants [5]. As a result, effective treatment of phenolic effluents is imperative before reuse or discharge [3]. There are a number of water purification techniques for treating phenolic effluents, such as adsorption [6] [7] [8], oxidation [9] [10] [11], extraction [12] [13], membrane separation [14] [15], photocatalytic degradation [16] [17], biological treatment [3] [18], and electrodialysis [19]. Among all the mentioned techniques, adsorption is one of the simplest, effective and economical methods for the removal of low concentrations of organic pollutants from large volumes of potable water, process effluents, wastewater, and aqueous solutions [20] [21].

Over the last century, activated carbon (AC) is consistently proved to be effective for the removal of phenol and its derivatives from industrial effluents [22] [23]. However, the disadvantage associated with $\mathrm{AC}$ lies in, the need for a costly regeneration system, the generation of carbons fines due to the brittle nature of carbons as well as its high initial manufacture cost [6] [7]. Furthermore, the production of AC generally involves high energy consumption processes and $\mathrm{CO}_{2}$ emissions, which make it difficult to meet the needs of low economic development and led many investigators to search low-cost adsorbents to remove phenols from wastewater.

As natural raw materials, minerals usually have thin or layered structure, and the space between layers helps them to act as carries to store gas [24] [25] or absorb organic [26] [27]. Shale is a fine-grained sedimentary rock and also a carrier of shale gas. Most previous studies on shale were conducted with a focus on methane adsorption and/or desorption behavior on shale matrix [24] [25]; however, there are few reports on the removal of phenolic contaminants by soils originated from natural shales. In this paper, soils developed on dolomitic shale (Yichang area, China) were used without any pretreatment to adsorption of phenol from simulated phenolic wastewaters. Effects of operating temperature, adsorbent dosage, contact time and $\mathrm{pH}$ on the phenol removal were experimentally investigated. Laboratory batch kinetics and isotherm studies as well as adsorption thermodynamics were conducted to evaluate the adsorption capacity of the soils.

\section{Experimental}

\subsection{Chemicals and Soil Samples}

Phenol, 4-aminoantipyrine, potassium ferricyanide, hydrochloric acid, sodium 
hydroxide and other inorganic chemicals were supplied by Aladdin Industrial Corporation (Shanghai, China), as analytical grade reagents. Shale outcrops of the Ediacaran Doushantuo Formation are distributed across a large part of South China [28]. The studied soils were developed on shale in the Yichang area, South China (as shown in Figure 1). All samples were air-dried, crushed with a mechanical rock crusher, ground in a ceramic mill, and then sieved to the desired particle size of $\sim 180 \mu \mathrm{m}$. Generally, the studied soils were kept in a desiccator over silica gel desiccant until use in characterization and adsorption experiments.

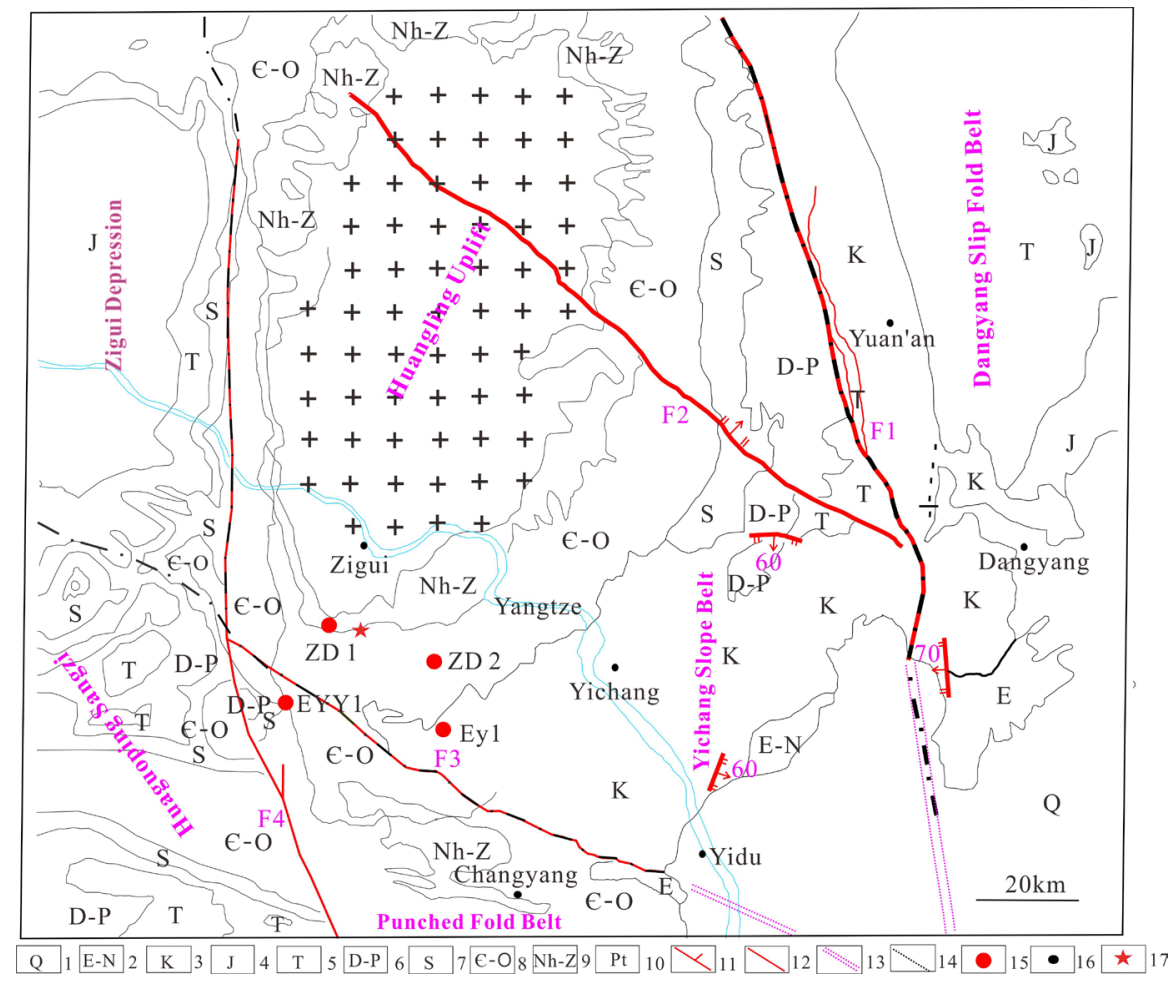

Figure 1. Geological map of the Yichang area, South China. 1-Quaternary; 2-Palaeocene-Neocene; 3-Cretaceous; 4-Jurassic; 5-Triassic; 6-Devonian-Permian; 7-Silurian; 8-Cambian-Ordovician; 9-Nanhua-Sinian; 10-Neoproterozoic granite; 11-Syncline axis; 12-Normal fault; 13-Unidentified fault; 14-Boundary of the structural unit; 15-Well name; 16-Area name; 17-Sampling site of shale. F1-Tongcheng river fault; F2-Wudu river fault; F3 - Tianyangping fault; F4-Xiannüfeng fault [29].

\subsection{Analytical Method}

The powder X-ray diffraction (XRD) data were collected at room temperature with a PANalytical X'Pert PRO X-ray diffractometer (PANalytical Co., Almelo, Netherlands). The $2 \theta$ Bragg angles were scanned over a range of $5^{\circ}-85^{\circ}$ at a scanning speed of $6.25^{\circ} / \mathrm{min}$. To obtain a quantitative measurement of the mineral components of a given sample, the maximum intensity of each identified mineral was measured and compared to the standard intensity obtained from a pure mineral sample. The FT-IR spectra were obtained in a diffuse reflectance infrared Fourier transform spectroscopy (DRIFTS) mode using the micro sam- 
pling cup of a Spectra-Tech diffuse reflectance accessory against a KBr background on a Nicolet 750 FT-IR spectrometer (Thermo Nicolet Corporation, Waltham, MA, DTGS detector; Nichrome source; KBr beam splitter). Morphology of the shale soils was observed by a field emission-scanning electron microscope (FE-SEM, Model MIRA3-XMU, TESCAN Czech Republic) operated at an acceleration voltage of $15 \mathrm{kV}$. The $\mathrm{N}_{2}$ adsorption-desorption isotherms can provide information on the total pore volume, specific surface area and pore size distribution of the shale soils. Samples were degassed at $140^{\circ} \mathrm{C}$ under a pressure of $0.334 \mathrm{MPa}$ for $2 \mathrm{~h}$ in nitrogen atmosphere before testing.

\subsection{Batch Adsorption Experiments}

In batch adsorption experiments, accurately weighed shale soils (1.0 - $3.0 \mathrm{~g})$ and $50 \mathrm{~mL}$ of the aqueous solution containing different initial concentrations of phenol $(10-300 \mathrm{mg} / \mathrm{L})$ were put into a glass-stoppered flask. The flask was darkly brown-colored to prevent photooxidation. The $\mathrm{pH}$ of the solution was adjusted with $\mathrm{HCl}$ or $\mathrm{NaOH}$ solution by using a $\mathrm{pH}$ meter (Model PB-10, Shanghai Cany Precision Instrument Co., Ltd., China). The flask was subsequently capped with the glass stopper and shaken in a temperature-controlled water bath shaker (Model SHA-B, Tianjin Saidlis Experimental Analytical Instrument Factory, China) for $2 \mathrm{~h}$ at the temperature range of $20^{\circ} \mathrm{C}-60^{\circ} \mathrm{C}$. At preset contact times, the concentrations of phenol in the solution were analyzed for residual concentration of phenol at $\lambda_{\max }=500 \mathrm{~nm}$ using a $722 \mathrm{~N}$ UV-vis spectrophotometer (Shanghai AuCy Scientific Instrument Co., Ltd, China) by the 4-aminoantipyrene method [30]. The amount adsorbed was calculated from the concentration of the phenol solution before and after the adsorption experiments using a Beer's law plot to interpolate concentrations. Phenol uptake at equilibrium, $\mathrm{q}_{\mathrm{e}}(\mathrm{mg} / \mathrm{g})$, was calculated by the equation, $\mathrm{q}_{\mathrm{e}}=\left(\mathrm{C}_{0}-\mathrm{C}_{\mathrm{e}}\right) \mathrm{V} / \mathrm{W}$. The $\mathrm{C}_{0}$ and $\mathrm{C}_{\mathrm{e}}(\mathrm{mg} / \mathrm{L})$ are the concentrations of phenol at initial and at equilibrium, respectively. $\mathrm{V}$ is the volume of the solution $(\mathrm{L})$ and $\mathrm{W}$ is the mass of dry adsorbent used (g). The calibration curves between absorbance and the concentration of the phenol solution were established. The calibration plot of absorbance versus concentration of phenol showed a linear variation. The standard curve was given as $y=0.0919 x-0.0002, R^{2}=0.992$, where $y$ is the absorbance and $x$ is the phenol concentration. All experiments were run in triplicates under identical conditions to ensure reproducibility, and sometimes repeated again and the mean values have been reported. Standard deviations were found to be within $\pm 3 \%$.

\section{Results and Discussions}

\subsection{Characterization of the Shale Soils}

The FT-IR spectra of the shale soil were presented in Figure 2. The broad and strong band in the range of $3150-3557 \mathrm{~cm}^{-1}$ was assigned to the -OH stretching vibration in hydroxyl groups of constitution water and interlayer water of clay minerals. The peaks at $1420 \mathrm{~cm}^{-1}, 872 \mathrm{~cm}^{-1}$ and $720 \mathrm{~cm}^{-1}$ were denoted as the 
stretching vibration of $\mathrm{C}-\mathrm{O}$ in the carbonate anion $\left(\mathrm{CO}_{3}{ }^{2-}\right)$ of dolomite [31]. The strong band in the range of $1000-1120 \mathrm{~cm}^{-1}$ was related to the $\mathrm{Si}-\mathrm{O}$ vibration in quartz and/or feldspar [32]. The peaks at $456-1000 \mathrm{~cm}^{-1}$ were assigned to the vibration of Si-O, Al-O-H and Si-O-Al [32]. The results of FTIR are further proved by XRD, as shown in Figure 3. The samples are mainly composed of mineral-like materials, and the quantitative mineralogical analyses demonstrated that the typical shale soil was mainly composed of dolomite (41.12 wt\%), quartz (28.78 wt\%), kaolinite (23.03 wt\%), analcime (2.30 wt\%) and plagioclase (4.76 $w t \%)$. This shale sample collected from outcrops of the Ediacaran Doushantuo Formation, south China is classified as dolomitic shale [29]. The SEM micrograph in Figure 4 was used to assess the morphological structure of the shale soil. It was demonstrated that the studied shale soil exhibited some visible fractures and layered structures with different diameters (Figure 4), possibly owing to the disintegration of the shale matrix. The well-developed structure of the shale soil was expected to potentially benefit absorption of phenols when it was applied to phenolic wastewater treatment.

The BET specific surface areas of the shale soil were determined as $19.287 \mathrm{~m}^{2} / \mathrm{g}$. The low-temperature nitrogen adsorption-desorption isotherms of the shale soil were shown in Figure 5, taking on an invert " $S$ " shape. The low-temperature nitrogen adsorption isotherms of the shale soil (Figure 5) exhibited a BET type

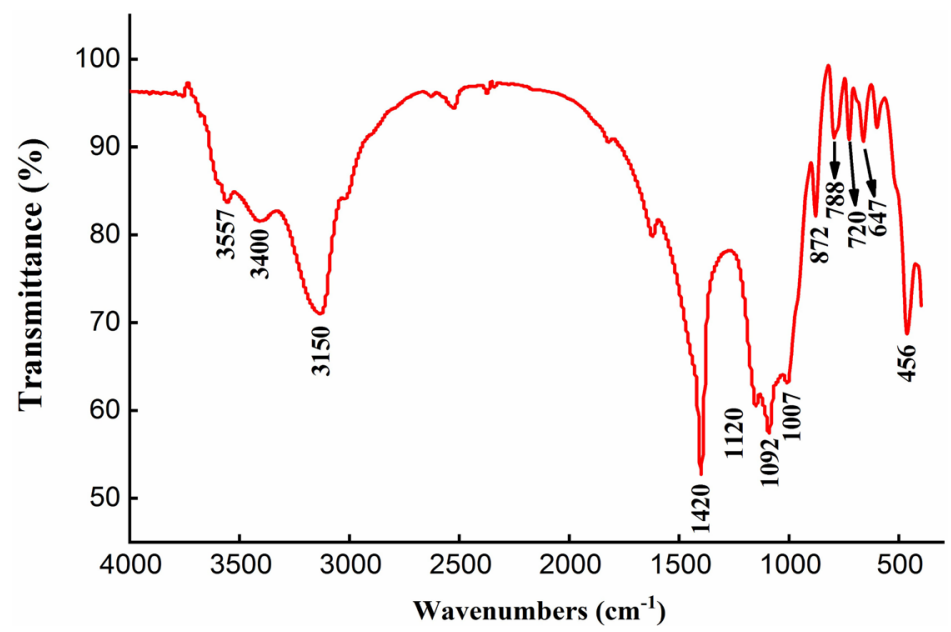

Figure 2. FT-IR spectra of the shale soil.

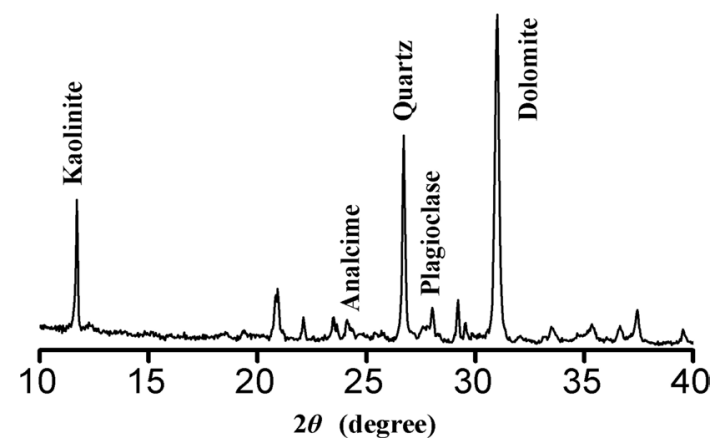

Figure 3. X-ray diffraction patterns of the shale soil. 


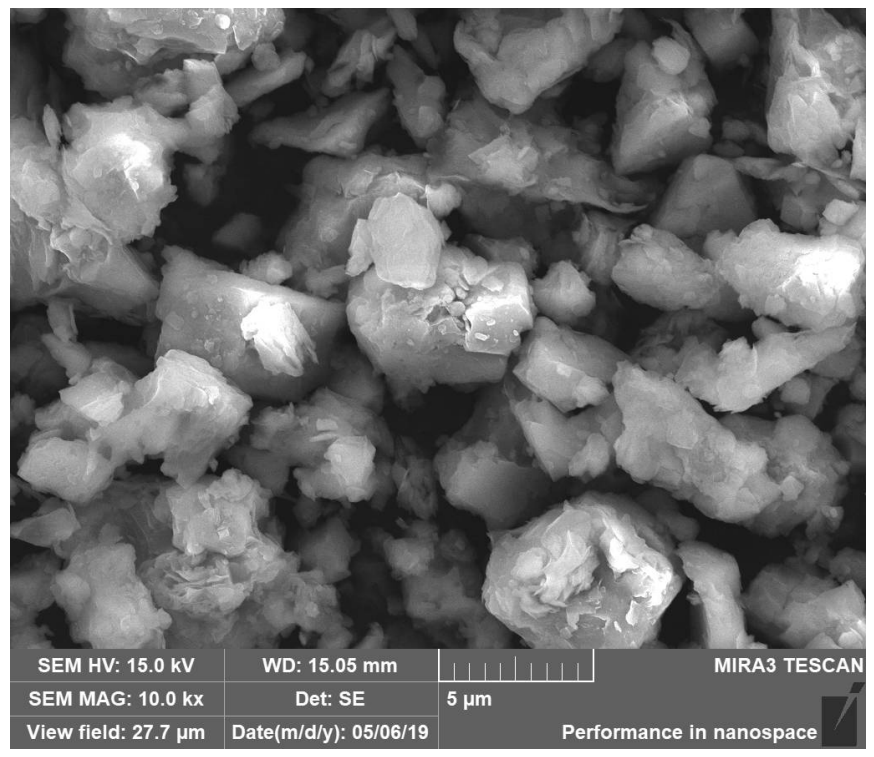

Figure 4. The SEM micrograph of the shale soil.

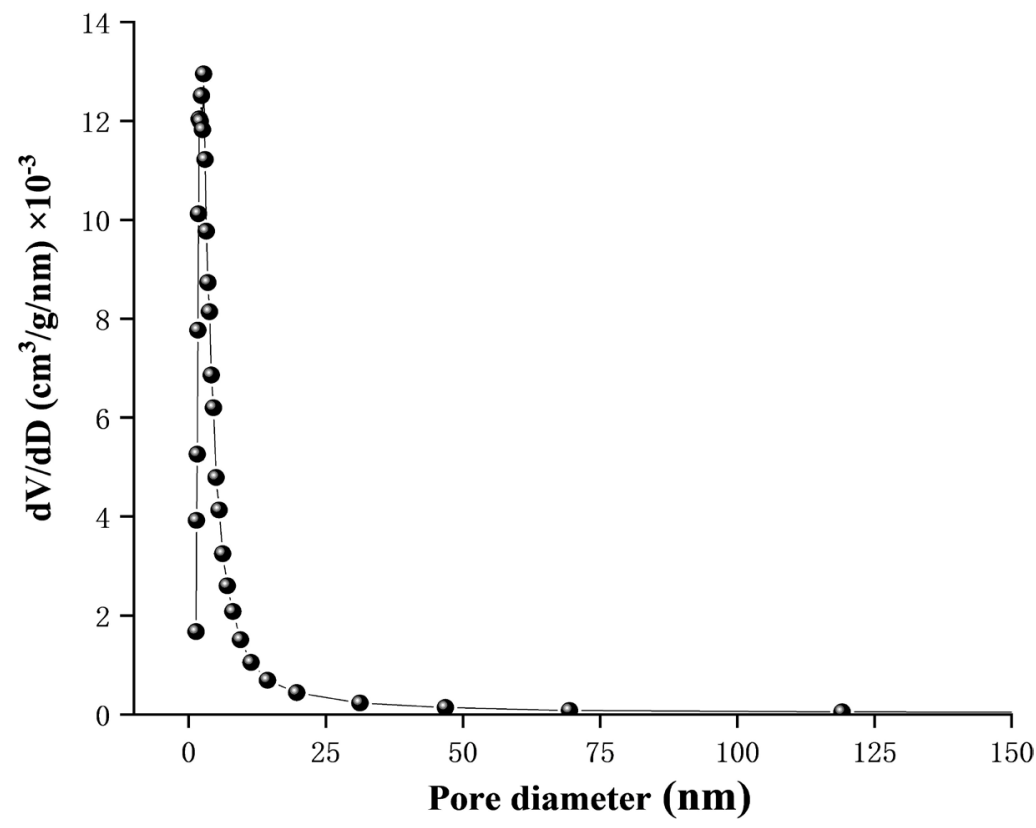

Figure 5. Nitrogen adsorption-desorption isotherms of the shale soil.

IV [33]. Within the lower range of $0-0.05$ for the relative pressure $\mathrm{p} / \mathrm{p} 0$, the adsorption isotherms of the shale soil protruded slightly upward, indicating monolayer adsorption occurring on the surface of the shale soil (Figure 5). When the relative pressure gradually increased to $0.05-0.6$, this change in slope of adsorption isotherm branch may be considered indicative of transition from monomolecular to multimolecular layer. When $\mathrm{p} / \mathrm{p}_{0}>0.8$, the adsorption branch ascended sharply, but did not reach a stable state even when $\mathrm{p} / \mathrm{p}_{0} \approx 1$ (Figure 5 ). This implied that nitrogen vapor confined in the pore of sample particles condensed at a pressure lower than its saturation pressure, which was called "capillary condensation". This phenomenon indicates the presence of a certain amount of 
mesopores and macropores in the studied shale soils [34] [35] [36]. As evidenced in Figure 5, desorption branches did not completely coincide with the corresponding adsorption branches, especially at the relatively high-pressure section $\left(\mathrm{p} / \mathrm{p}_{0}>0.6\right)$. The adsorption and desorption isotherms formed a hysteresis loop. This hysteresis loop was classified as type H3 according to IUPAC classification [33], implying micropores developed in the shale soil [37]. Pore size distributions (PSDs) were calculated using the BJH (Barrett-Joyner-Halenda) method and shown in Figure 6. It was found that the PSDs of the shale soil was mainly limited within the range of $1.78-5.54 \mathrm{~nm}$ and peaked at $2.74 \mathrm{~nm}$ (Figure 6). An average pore size of $10.99 \mathrm{~nm}$ was obtained by averaging $\mathrm{BJH}$ values from the isotherms.

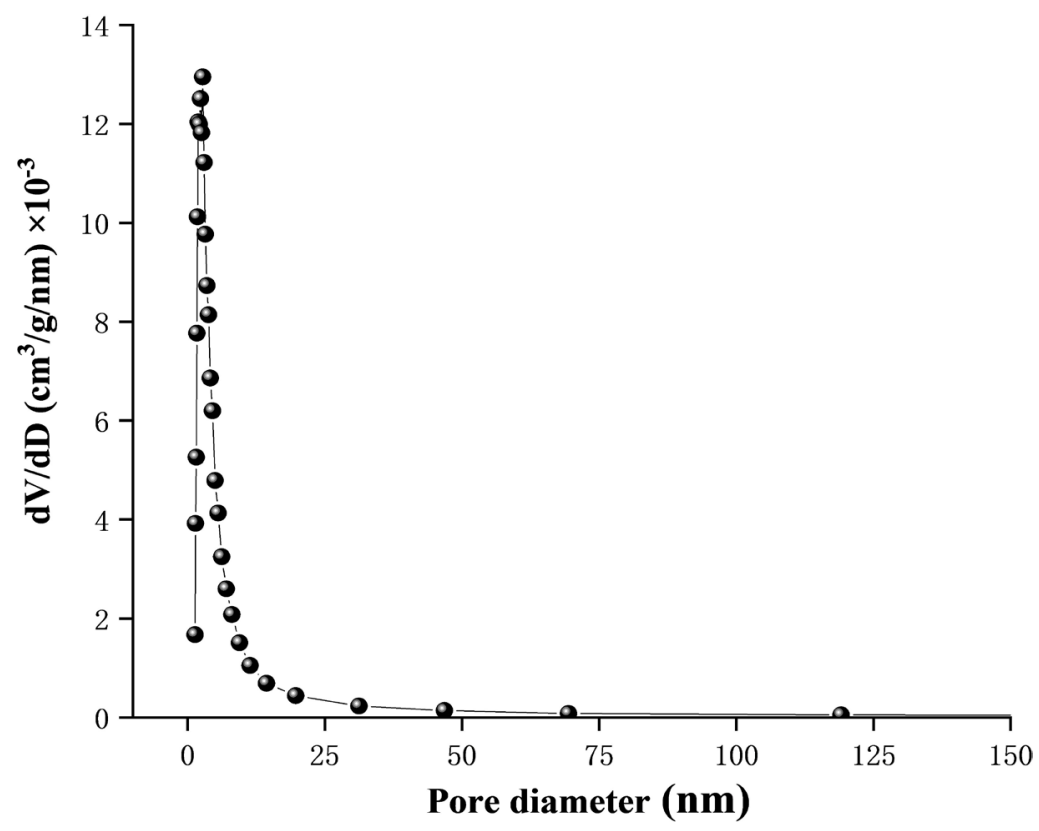

Figure 6. Pore size distribution of the shale soil.

\subsection{The Orthogonal Test of Phenol Removal by Natural Shale Soils}

The orthogonal test (Table 1) with four factors and five levels was designed to analyze the main influencing factors on the phenol removal by the shale soil. The selected factors included adsorbent dose, contact time, operating temperature and $\mathrm{pH}$. It was found that the operating temperature and adsorbent dose with range values of 31.16 and 12.98, respectively, were the key factors affecting the phenol adsorption on the shale soil (Table 2). $\mathrm{pH}$ did not significantly affect the phenol removing within the scope of 3.0 - 11.0. Furthermore, the contact time of $60 \mathrm{~min}$ was sufficient to assure progress to the adsorption of phenol by the shale soil, and the extra time would be not needed. These contact time and $\mathrm{pH}$ showed subordinate factors on the phenol removing, which can be proved from their low range values of 7.31 and 3.96, respectively (Table 2). Therefore, the order of influencing factors on the phenol removal can be obtained as follows: operating temperature $>$ adsorbent dosage $>$ contact time $>\mathrm{pH}$. 
Table 1. The orthogonal test scheme of 4 factors and 5 levels.

\begin{tabular}{rrrrr}
\hline \multirow{2}{*}{ Levels } & & & Factors \\
\cline { 2 - 5 } & Dosage $(\mathrm{g})$ & Contact time $(\mathrm{min})$ & Temperature $\left({ }^{\circ} \mathrm{C}\right)$ & $\mathrm{pH}$ \\
\hline 1 & 1.0 & 30 & 20 & 3 \\
2 & 1.5 & 45 & 30 & 5 \\
3 & 2.0 & 60 & 40 & 7 \\
4 & 2.5 & 75 & 50 & 9 \\
5 & 3.0 & 90 & 60 & 11 \\
\hline
\end{tabular}

Table 2. Range analysis of the orthogonal test.

\begin{tabular}{|c|c|c|c|c|c|}
\hline No. & Dosage & Contact time & Temperature & $\mathrm{pH}$ & Phenol removal efficiency (\%) \\
\hline 1 & 1 & 1 & 1 & 1 & 18.17 \\
\hline 2 & 1 & 2 & 2 & 2 & 15.56 \\
\hline 3 & 1 & 3 & 3 & 3 & 2.63 \\
\hline 4 & 1 & 4 & 4 & 4 & 36.56 \\
\hline 5 & 1 & 5 & 5 & 5 & 6.00 \\
\hline 6 & 2 & 1 & 2 & 3 & 17.34 \\
\hline 7 & 2 & 2 & 3 & 4 & 7.72 \\
\hline 8 & 2 & 3 & 4 & 5 & 36.76 \\
\hline 9 & 2 & 4 & 5 & 1 & 4.96 \\
\hline 10 & 2 & 5 & 1 & 2 & 40.50 \\
\hline 11 & 3 & 1 & 3 & 5 & 7.92 \\
\hline 12 & 3 & 2 & 4 & 1 & 38.14 \\
\hline 13 & 3 & 3 & 5 & 2 & 8.30 \\
\hline 14 & 3 & 4 & 1 & 3 & 38.92 \\
\hline 15 & 3 & 5 & 2 & 4 & 24.78 \\
\hline 16 & 4 & 1 & 4 & 2 & 45.40 \\
\hline 17 & 4 & 2 & 5 & 3 & 11.64 \\
\hline 18 & 4 & 3 & 1 & 4 & 32.64 \\
\hline 19 & 4 & 4 & 2 & 5 & 32.24 \\
\hline 20 & 4 & 5 & 3 & 1 & 18.32 \\
\hline 21 & 5 & 1 & 5 & 4 & 15.56 \\
\hline 22 & 5 & 2 & 1 & 5 & 25.38 \\
\hline 23 & 5 & 3 & 2 & 1 & 39.12 \\
\hline 24 & 5 & 4 & 3 & 2 & 18.32 \\
\hline 25 & 5 & 5 & 4 & 3 & 45.40 \\
\hline K1 & 15.78 & 20.88 & 31.12 & 23.74 & \\
\hline K2 & 21.45 & 19.69 & 25.81 & 25.62 & \\
\hline K3 & 23.61 & 23.90 & 10.98 & 23.19 & \\
\hline K4 & 28.05 & 26.20 & 40.45 & 23.45 & - \\
\hline K5 & 28.76 & 27.00 & 9.29 & 21.66 & \\
\hline Range (R) & 12.98 & 7.31 & 31.16 & 3.96 & \\
\hline
\end{tabular}

Note: $K$ : sum of each level; Rang $=K_{\max }-K_{\min }$; removal efficiencies are average values. 


\subsection{Adsorption Kinetics}

The adsorption kinetic characteristics are important for providing valuable insights into the adsorption mechanisms [38]. The experimental kinetic data of adsorption of phenols onto the shale soil were examined using the pseudo-first-order and pseudo-second-order equations [39]. The pseudo-first-order kinetic equation is expressed by

$$
q_{\mathrm{t}}=q_{\mathrm{e}}\left(1-e^{-k_{1} t}\right)
$$

The pseudo-second-order kinetic equation is expressed by

$$
q_{\mathrm{t}}=\frac{q_{\mathrm{e}}^{2}}{1+q_{\mathrm{e}} k_{2} t} k_{2} t
$$

where $q_{\mathrm{e}}$ and $q_{\mathrm{t}}$ are the amount of phenol adsorbed per unit mass of the adsorbent $(\mathrm{mg} / \mathrm{g})$ at equilibrium and time $t$ respectively. $k_{1}\left(\mathrm{~min}^{-1}\right)$, and $k_{2}(\mathrm{~g}(\mathrm{mg} \cdot \mathrm{min}))$ are the pseudo-first-order and pseudo-second-order rate constant, respectively. The fitting results of the adsorption kinetics were shown in Figure 7 and Table 3.
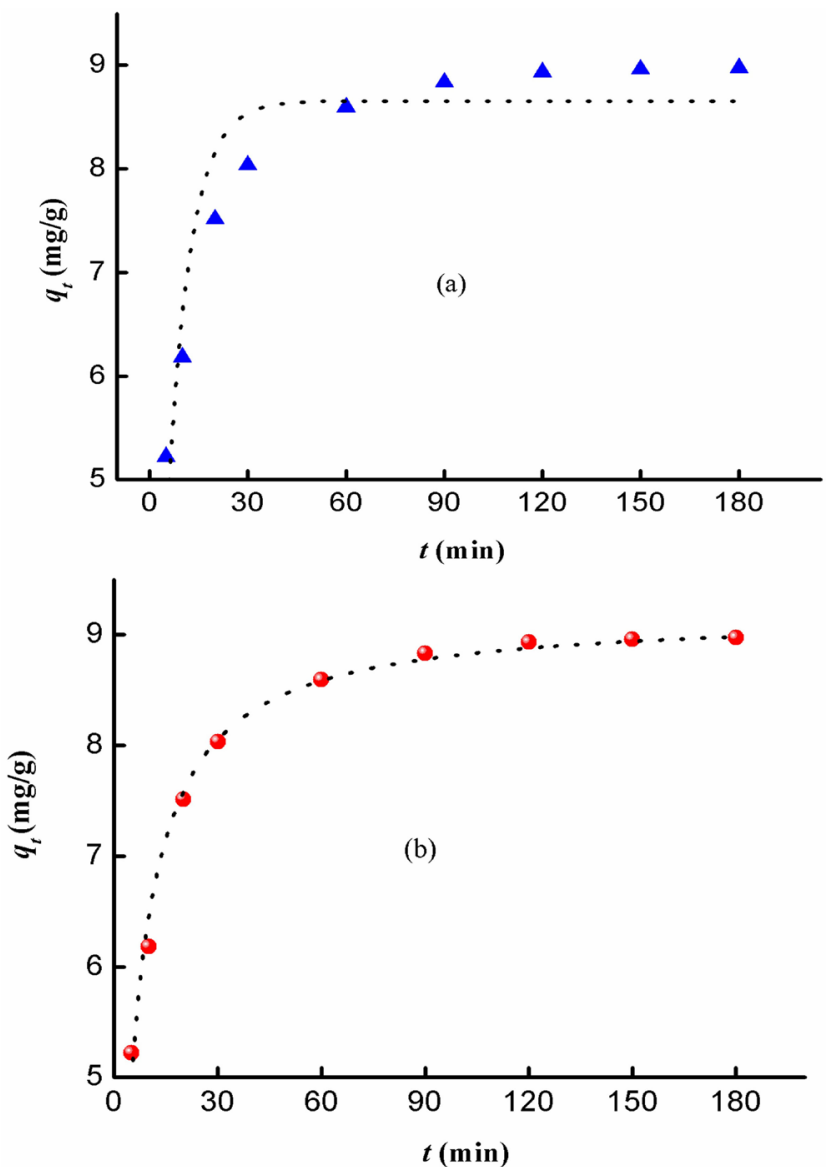

Figure 7. Kinetic plots of phenol adsorption on shale soil: (a) Pseudo-first-order model; (b) Pseudo-second-order model.

It was found that the correlation coefficient $\left(R^{2}\right)$ values of the pseudo-second-order were higher than that of the pseudo-first-order kinetics model 
(Table 3). This demonstrated that the pseudo-second-order model fitted well with the adsorption experimental data and can be used for the entire adsorption process (Figure 7). Our kinetic results for the adsorption of phenol by the shale soil are consistent with some previous studies using natural soil [40] and natural zeolite [41]. The overall rate of adsorption may involve surface diffusion, pore diffusion and adsorption on the interior sites of the sorbent [42]. The kinetic process that is fitted by the pseudo-second-order kinetic model has chemisorption as the rate-determining step and involves valency forces by sharing or through the exchange of electrons between the shale soils and phenols as covalent forces [43]. The actual adsorption sites of the soils may be associated with the organic matter within the shale soil, in which case phenol would be attracted by their similar aromatic character. Generally, the adsorption capacity of the natural shale soil for phenol increases with the increasing time and becomes constant after the equilibrium time is reached. Evidently, a large number of active sites are available on the surface of the shale soil in the initial stages, resulting in its high phenol adsorption capacity and the occurrence of rapid adsorption. Thereafter, the uptake of phenols becomes slower before a dynamic equilibrium is attained. This may be due to the gradual diminishing of the surface sites and the increasing steric repulsion among the phenol molecules on the soil surface and the incoming ones from the solution.

Table 3. Parameters of adsorption kinetics.

\begin{tabular}{rrrrrr}
\hline \multicolumn{3}{c}{ Pseudo-first-order kinetic model } & \multicolumn{3}{c}{ Pseudo-second-order kinetic model } \\
\hline $\boldsymbol{q}_{\mathrm{e}}(\mathrm{mg} / \mathrm{g})$ & $\boldsymbol{k}_{1}\left(\mathrm{~min}^{-1}\right)$ & $\boldsymbol{R}^{2}$ & $\boldsymbol{q}_{\mathrm{e}}(\mathrm{mg} / \mathrm{g})$ & $\boldsymbol{k}_{2}(\mathrm{~g} /(\mathrm{mg} \cdot \mathrm{min}))$ & $\boldsymbol{R}^{2}$ \\
\hline 8.65 & 0.144 & 0.8815 & 9.19 & 0.256 & 0.990 \\
\hline
\end{tabular}

\subsection{Adsorption Isotherms}

Several isotherm models have been reported [44] to describe experimental data of adsorption equilibriums including Langmuir, Freundlich, Redlich-Peterson, Sip isotherms, etc. The Langmuir isotherm is the most widely used two-parameter equation, and assumes the following hypotheses: uniform adsorption energies along the homogeneous adsorbent surface, equal solute affinity in all the adsorption sites, no interaction among adsorbed molecules, single adsorption mechanism, and formation of a monolayer on the free surface [22] [30] [45] [46] [47]. The Freundlich isotherm is used for modelling the adsorption on heterogeneous surfaces. This experimental model can be applied to nonideal sorption on heterogeneous surfaces as well as multi-layer sorption [41] [48] [49] [50]. The Redlich-Peterson isotherm model is an empirical isotherm incorporating three parameters. It combines elements from both the Langmuir and Freundlich equations, and the mechanism of adsorption is a hybrid and does not follow ideal monolayer [40]. The Sip model equation follows Freundlich isotherm at lower solute concentration and obeys Langmuir isotherm at higher solute concentration [40]. A statistical analysis of the adsorption isotherms reveals that Langmuir 
and Freundlich are the most examined models in fitting the experimental adsorption data [8]. Accordingly, in this study the sorption data of phenols were correlated with these two isotherms (Equations (3) and (4)).

Langmuir equation:

$$
\frac{C_{\mathrm{e}}}{q_{\mathrm{e}}}=\frac{C_{\mathrm{e}}}{q_{\max }}+\frac{1}{K_{\mathrm{L}} \times q_{\max }}
$$

where $C_{\mathrm{e}}$ is the equilibrium concentration of phenol in solutions $(\mathrm{mg} / \mathrm{L}), q_{\mathrm{e}}$ is the amount of phenol adsorbed per unit mass of the adsorbent at equilibrium state $(\mathrm{mg} / \mathrm{g}), q_{\max }$ is the maximum adsorption capacity $(\mathrm{mg} / \mathrm{g}) . K_{\mathrm{L}}$ is the Langmuir equilibrium constant related to the affinity of binding sites and energy of adsorption $(L /(\mathrm{mg} \cdot \mathrm{min})) . K_{\mathrm{F}}$ is the Freundlich constant $(L /(\mathrm{mg} \cdot \mathrm{min}))$, indicating the adsorption capacity of the adsorbent and $n$ (dimensionless) is a constant related to the intensity of adsorption.

Freundlich equation:

$$
\lg q_{\mathrm{e}}=\frac{\lg C_{\mathrm{e}}}{n}+\lg K_{\mathrm{F}}
$$

The fitting results of the adsorption isotherms were shown in Figure 8 and Table 4 . The $R^{2}$ values of the Freundlich model were generally higher than those
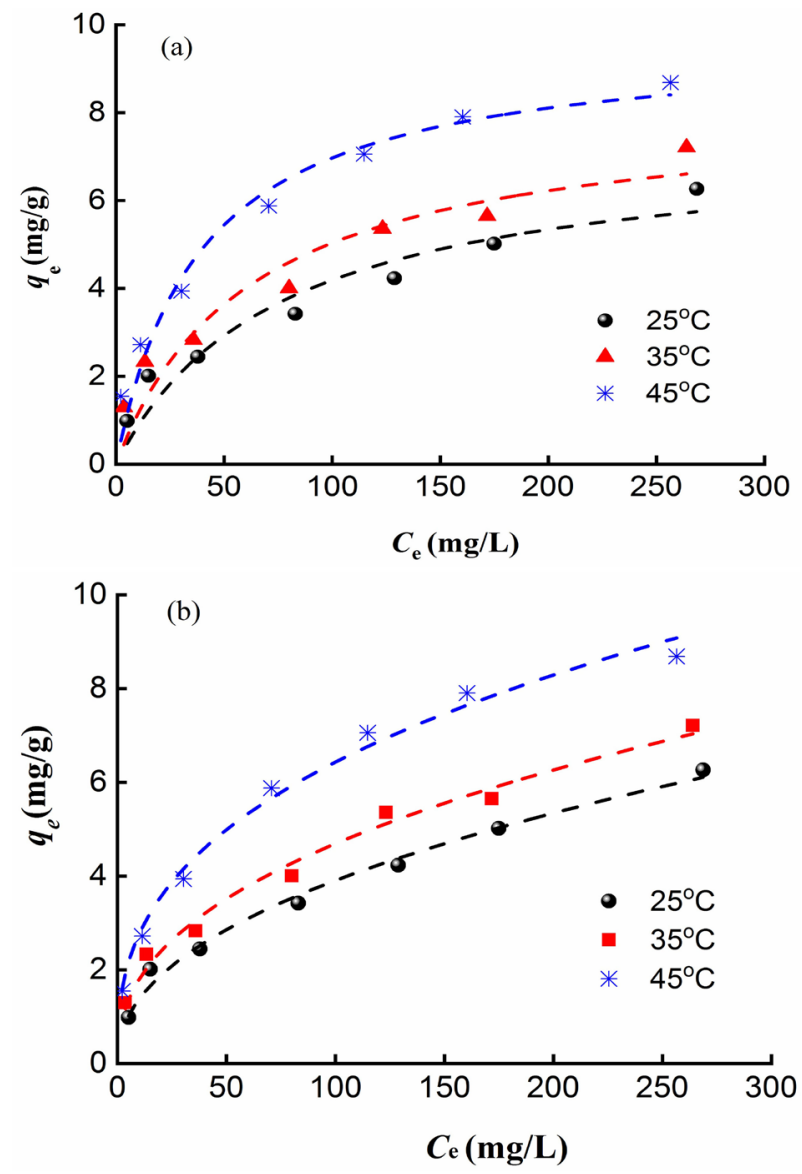

Figure 8. Adsorption isotherms of phenol on the shale soil: (a) Langmuir model; (b) Freundlich model. 
Table 4. Parameters of adsorption isotherm models at various temperatures.

\begin{tabular}{rrrrrrr}
\hline \multirow{5}{*}{\begin{tabular}{r} 
Temperature \\
\cline { 2 - 8 }$\left({ }^{\circ} \mathrm{C}\right)$
\end{tabular}} & $\begin{array}{r}\mathrm{K}_{\mathrm{L}} \\
(\mathrm{L} /(\mathbf{m g} \cdot \mathrm{min}))\end{array}$ & $\begin{array}{r}\mathbf{q}_{\max } \\
(\mathrm{mg} / \mathrm{g})\end{array}$ & $\mathbf{R}^{2}$ & $\begin{array}{r}\mathrm{K}_{\mathrm{F}} \\
(\mathrm{L} /(\mathrm{mg} \cdot \mathrm{min}))\end{array}$ & $\mathbf{n}$ & $\mathbf{R}^{2}$ \\
\hline 25 & 0.0132 & 7.36 & 0.924 & 0.486 & 2.212 & 0.989 \\
35 & 0.0161 & 8.15 & 0.910 & 0.688 & 2.404 & 0.986 \\
45 & 0.0258 & 9.68 & 0.963 & 1.19 & 2.732 & 0.990 \\
\hline
\end{tabular}

of the Langmuir model for the adsorption of phenol onto the natural shale soil (Table 4). Evidently, the Freundlich model can be applied to describe experimental data of adsorption equilibriums during phenol removal by the shale soil. This is in accordance with the heterogeneity of the shale soil structures characterized by FE-SEM (Figure 4). Moreover, the increasing values of $\mathrm{q}_{\mathrm{e}}$ and $\mathrm{n}$ with the increase of temperatures in Table 4 indicate that phenol removal by the shale soil is favored at elevated temperatures under the constrained batch experiments [51]. Nayak and Singh [30] presented that higher temperatures promote the rupture of hydrogen bonds between the phenol molecule and water, causing more phenol adsorbed by the adsorbent rather remaining in the aqueous solution.

\subsection{Adsorption Thermodynamics}

The feasibility of adsorption of phenols on the shale soil surface can be evaluated by exploring the thermodynamics parameters. Energetic changes during adsorption in terms of considering amount of heat being absorbed or released, dispersal of energy and amount of energy associated with the adsorption are quantified by standard enthalpy $\left(H^{\circ}\right)$, standard entropy $\left(S^{\circ}\right)$ and Gibbs free energy $\left(G^{\circ}\right)$ respectively. These parameters are essential for indicating the spontaneity and/or possibility of adsorption mechanism and defining the exothermic and endothermic adsorption processes [8].

According to Van't Hoff Equation (5), the Gibbs free energy change of adsorption $\Delta G^{\circ}(\mathrm{kJ} / \mathrm{mol})$ for the adsorption of phenol onto the shale soil was calculated using Equation (5) and shown in Table 5.

$$
\Delta G^{\circ}=-R T \ln K_{\mathrm{F}}
$$

where $R$ is the universal gas constant $(8.314 \mathrm{~J} /(\mathrm{mol} \cdot \mathrm{K})), T$ is the absolute temperature and $K_{\mathrm{F}}$ is the Freundlich constant. Temperature $T$ was plotted against $\Delta G^{\circ}$ based on the following basic thermodynamic equation:

$$
\Delta G^{\circ}=\Delta H^{\circ}-T \Delta S^{\circ}
$$

The values of the enthalpy $\left(\Delta H^{\circ}, \mathrm{kJ} / \mathrm{mol}\right)$ and entropy $\left(\Delta S^{\circ}, \mathrm{J} /(\mathrm{mol} \cdot \mathrm{K})\right)$ could be obtained from the slope and intercept of the line in Figure 9 and then listed in Table 5.

Values of $\Delta \mathrm{G}^{\circ}$ are significantly smaller than $50 \mathrm{KJ} / \mathrm{mol}$ (Table 5 ). This indicates that the adsorption of phenol onto the studied shale soil surface is thermodynamically possible. Moreover, the magnitude of $\Delta \mathrm{G}^{\circ}$ decreased with an in- 
crease in the temperature denoting that the adsorption is more favorable at higher temperature range of $25^{\circ} \mathrm{C}-45^{\circ} \mathrm{C}$. The value of $\Delta \mathrm{H}^{\circ}$ is positive, implying the endothermic nature of the adsorption of phenol onto the shale soils. One possible explanation of endothermicity of the enthalpy of adsorption is due to the reason that hydrogen bonds were formed between phenol and water molecules [52]. Phenols would not be adsorbed by the shale soil until the hydrogen bonds were destroyed. This rupture of hydrogen bonds between phenol and water molecules obviously required energy [53]. Therefore, it is reasonably assumed that this energy of hydrogen-bond breaking exceeded the exothermicity of the phenol attaching to the surface of the shale soil. The positive values of $\Delta S^{\circ}$ indicate increase in randomness at the interface of the solid soil/liquid water during the adsorption process and show the good affinity of the soils for the adsorbed phenols. It should be noted that a chemisorbed layer could be followed by the physically adsorbed layer which may not be excluded in this study.

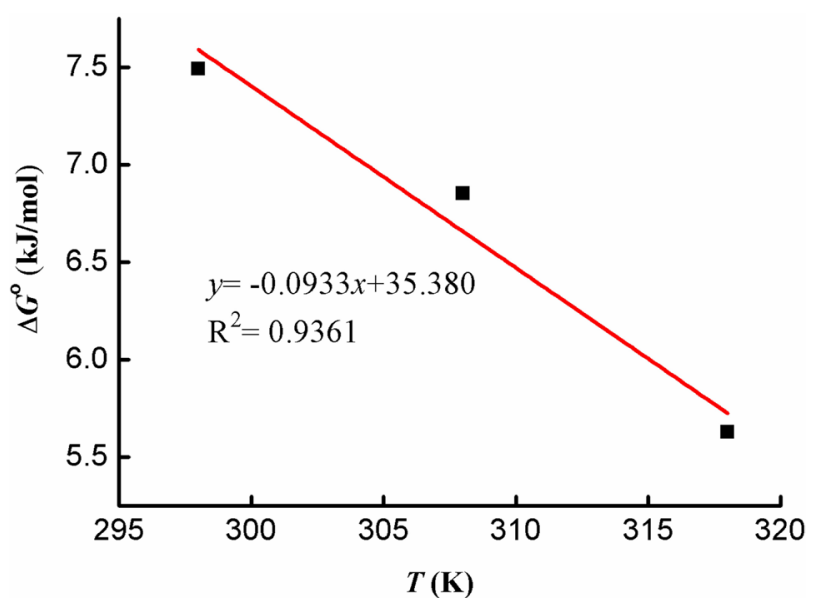

Figure 9. Plot of $\Delta G^{\circ}$ versus $T$.

Table 5. Thermodynamic parameters for adsorption.

\begin{tabular}{rrrr}
\hline$T(\mathrm{~K})$ & $\Delta G^{\circ}(\mathrm{kJ} / \mathrm{mol})$ & $\Delta H^{\circ}(\mathrm{kJ} / \mathrm{mol})$ & $\Delta S^{\circ}(\mathrm{J} /(\mathrm{mol} \cdot \mathrm{K}))$ \\
\hline 298 & 7.493 & & \\
308 & 6.854 & 35.38 & 93.30 \\
318 & 5.628 & & \\
\hline
\end{tabular}

\subsection{Comparison with Other Studies Using Natural Materials}

Various chemical, thermal and/or biological pretreatments had been utilized to improve the adsorption capacity of the low-cost materials for phenol removal. The modification methods always resulted in the increase of manufacturing cost as well as difficulties in regeneration/disposal of the adsorbents [40]. Notably, some previous researchers investigated the adsorption of phenol by naturally occurring adsorbents under the constrained experimental conditions. Typical experimental results were listed in Table 6. Isotherm models are selected to report based on their fitting performance with the experimental data. As shown in 
Table 6, the Langmuir and Freundlich models are the most frequently employed to describe the relationship between the amount of phenol adsorbed by naturally occurring adsorbents and its equilibrium concentration in solutions under different experimental conditions. The present study revealed that the Freundlich adsorption isotherm model could better describe the adsorption of phenol on the shale soil surface than the Langmuir adsorption isotherm model. Our finding is in agreement with some previous studies using natural bentonite [49] [54], clinoptylolite [55], siltstone [48], raw lignite [50], kaolinite [47] [56], spent oil shale [57], soil [56], peat [58], natural zeolite [41] and zeolitic tuff [41]. In comparison with studies on adsorption isotherms, adsorption kinetics for phenol removal by natural materials were far less documented. It can be summarized from Table 6 that adsorption mechanism of phenol is best described by pseudo-second-order [40] [41], pseudo-first-order [22] [50] and Elovich equations [59]. Considering different experimental conditions (e.g., temperature, contact

Table 6. Comparison of phenol adsorption on various naturally occurring adsorbents.

\begin{tabular}{|c|c|c|c|c|}
\hline Sorbent & Isotherm model & Kinetic model & $\begin{array}{r}\text { Capacity } \\
(\mathrm{mg} / \mathrm{g})\end{array}$ & Reference \\
\hline Bentonite & Langmuir, Freundlich & - & 1.7 & {$[54]$} \\
\hline Bentonite & Langmuir, Freundlich,Temkin & - & 66.67 & [49] \\
\hline Bentonite & Freundlich & - & 0.015 & [58] \\
\hline Bentonite & Langmuir & - & 15 & {$[62]$} \\
\hline Clay & Langmuir & - & 30.33 & {$[30]$} \\
\hline Clinoptylolite & Freundlich & - & 0.23 & {$[55]$} \\
\hline Coal & Redlich-Peterson & Pseudo-first-order & 13.28 & {$[22]$} \\
\hline Coal & Langmuir & - & 0.24 & {$[60]$} \\
\hline $\begin{array}{c}\text { Granite residual } \\
\text { Soil }\end{array}$ & Langmuir, Freundlich & - & 0.245 & {$[56]$} \\
\hline Kaolin & Langmuir & Elovich & 41.0 & [59] \\
\hline Kaolinite & Langmuir, Freundlich & - & 1.28 & [47] \\
\hline Kaolinite & Langmuir, Freundlich & - & 0.028 & {$[56]$} \\
\hline Lignite & Freundlich & Pseudo-first-order & 10.0 & {$[50]$} \\
\hline Montmorillonite & Langmuir & Elovich & 40.4 & [59] \\
\hline Peat & Freundlich & - & 0.1 & [58] \\
\hline Siltstone & Langmuir, Freundlich & - & 0.28 & {$[48]$} \\
\hline Soil (Ar) & Redlich-Peterson, Sip & Pseudo-second-order & 34.27 & {$[40]$} \\
\hline Soil (Kr) & Redlich-Peterson, Sip & Pseudo-second order & 51.83 & {$[40]$} \\
\hline Spent oil shale & $\begin{array}{l}\text { Frendlich, Langmuir, } \\
\text { Redlich-Peterson }\end{array}$ & - & 1.0 & [57] \\
\hline Zeolitic tuff & $\begin{array}{l}\text { Langmuir, Freundlich, } \\
\text { Redlich-Peterson, Temkin }\end{array}$ & Pseudo-second-order & 34.5 & [41] \\
\hline Shale soil & Freundlich & pseudo-second-order & 9.68 & This study \\
\hline
\end{tabular}


time, $\mathrm{pH}$, concentration ranges of phenol) utilized in adsorption experiments, it is not ready to compare adsorption performance of various natural materials. However, the studied shale soils showed a relatively higher equilibrium capacity (of an order of magnitude of $10 \mathrm{mg} / \mathrm{g}$, Table 6) than those of other natural materials including clinoptylolite [55], siltstone [48], spent oil shale [57], granite residual soil [56], clays [47] [54] [56] [58] and coals [58] [60].

It should be pointed out that direct utilization of the studied shale soils without surface modification does not seem viable for the effective treatment of high concentration phenolic effluents from chemical and allied industries (200 - 2000 $\mathrm{mg} / \mathrm{L}$ ) [22]. Nevertheless, the studied soils, which are developed on the natural shale widespread in South China, are promising candidates for advanced removal of trace phenol from mass production of potable and mineral waters, considering the limit for phenols in potable and mineral waters is $0.5 \mu \mathrm{g} / \mathrm{L}(0.5 \mathrm{ppb})$ recommended by the European Union [61].

\section{Conclusion}

In the present study, laboratory experiments were performed to evaluate the use of shale soils as an adsorbent for phenols in aqueous solution. It was found that the factors affecting the adsorption of phenol by the shale soil are temperature $>$ dosage $>$ adsorption time $>\mathrm{pH}$. The studied shale soils exhibited small fragments and well-developed pore structures with different diameters. The pore size distributions of the samples were mainly limited within the range of 1.78 $5.54 \mathrm{~nm}$ and peaked at $2.74 \mathrm{~nm}$. Thermodynamic analysis showed that the adsorption of phenol by the shale soil is the endothermic process, and the higher temperature in the range of $25^{\circ} \mathrm{C}-45^{\circ} \mathrm{C}$ favored the adsorption process. The entire adsorption kinetic process follows the pseudo-second-order model, which has chemisorption as the rate-determining step. Investigation of adsorption thermodynamics indicates that Freundlich isotherm model gives a better description for the isotherm curve than the Langmuir model, consistent with the heterogeneity of shale soils in physical-chemical properties. Results of our study indicate potential utilization of natural shale soils as a promising low-cost absorbent for trace phenol removal from mass production of potable and mineral waters. Utilization of naturally occurring adsorbents undoubtedly benefits the maintenance of a healthy surrounding environment as well as the sustainable development of economy.

\section{Acknowledgements}

We gratefully acknowledge financial support by the National Natural Science Foundation of China (No. 41472095), the Open Fund of Key Laboratory of Exploration Technologies for Oil and Gas Resources (Yangtze University), Ministry of Education (No. K2018-05) and the Open Fund of Shandong Provincial Key Laboratory of Depositional Mineralization \& Sedimentary Minerals, Shandong University of Science and Technology (Grant No. DMSM2018041). 


\section{Conflicts of Interest}

The authors declare no conflicts of interest regarding the publication of this paper.

\section{References}

[1] Duan, W., Meng, F., Cui, H., Lin, Y., Wang, G. and Wu, J. (2018) Ecotoxicity of Phenol and Cresols to Aquatic Organisms: A Review. Ecotoxicology and Environmental Safety, 157, 441-456. https://doi.org/10.1016/j.ecoenv.2018.03.089

[2] Autenrieth, R.L. and Bonner, J.S. (1991) Biodegradation of Phenolic Wastes. Journal of Hazardous Materials, 28, 29-53. https://doi.org/10.1016/0304-3894(91)87004-L

[3] Alshabib, M. and Onaizi, S.A. (2019) A Review on Phenolic Wastewater Remediation Using Homogeneous and Heterogeneous Enzymatic Processes: Current Status and Potential Challenges. Separation and Purification Technology, 219, 186-207. https://doi.org/10.1016/j.seppur.2019.03.028

[4] Rubalcaba, A., Suárez-Ojeda, M.E., Carrera, J., Font, J., Stüber, F., Bengoa, C., Fortuny, A. and Fabregat, A. (2007) Biodegradability Enhancement of Phenolic Compounds by Hydrogen Peroxide Promoted Catalytic Wet Air Oxidation. Catalysis Today, 124, 191-197. https://doi.org/10.1016/j.cattod.2007.03.037

[5] Zhong, W., Wang, D. and Xu, X. (2012) Phenol Removal Efficiencies of Sewage Treatment Processes and Ecological Risks Associated with Phenols in Effluents. Journal of Hazardous Materials, 217-218, 286-292. https://doi.org/10.1016/j.jhazmat.2012.03.026

[6] Ahmaruzzaman, M. (2008) Adsorption of Phenolic Compounds on Low-Cost Adsorbents: A Review. Advances in Colloid and Interface Science, 143, 48-67. https://doi.org/10.1016/j.cis.2008.07.002

[7] Lin, S.H. and Juang, R.S. (2009) Adsorption of Phenol and Its Derivatives from Water Using Synthetic Resins and Low-Cost Natural Adsorbents: A Review. Journal of Environmental Management, 90, 1336-1349. https://doi.org/10.1016/j.jenvman.2008.09.003

[8] Awad, A.M., Shaikh, S.M.R., Jalab, R., Gulied, M.H., Nasser, M.S., Benamor, A. and Adham, S. (2019) Adsorption of Organic Pollutants by Natural and Modified Clays: A Comprehensive Review. Separation and Purification Technology, 228, Article ID: 115719. https://doi.org/10.1016/j.seppur.2019.115719

[9] Luan, M., Jing, G., Piao, Y., Liu, D. and Jin, L. (2017) Treatment of Refractory Organic Pollutants in Industrial Wastewater by Wet Air Oxidation. Arabian Journal of Chemistry, 10, S769-S776. https://doi.org/10.1016/j.arabjc.2012.12.003

[10] Shao, Y. and Chen, H. (2018) Heterogeneous Fenton Oxidation of Phenol in Fixed-Bed Reactor Using Fe Nanoparticles Embedded within Ordered Mesoporous Carbons. Chemical Engineering Research and Design, 132, 57-68. https://doi.org/10.1016/j.cherd.2017.12.039

[11] Sushma, Kumari, M. and Saroha, A.K. (2018) Performance of Various Catalysts on Treatment of Refractory Pollutants in Industrial Wastewater by Catalytic Wet Air Oxidation: A Review. Journal of Environmental Management, 228, 169-188. https://doi.org/10.1016/j.jenvman.2018.09.003

[12] Guo, C., Cao, Q., Chen, B., Yang, S. and Qian, Y. (2019) Development of Synergistic Extraction Process for Highly Efficient Removal of Phenols from Coal Gasification Wastewater. Journal of Cleaner Production, 211, 380-386. https://doi.org/10.1016/j.jclepro.2018.11.227 
[13] Chen, Y., Xiong, K., Jiang, M. and Lv, R. (2019) Phase Equilibrium Measurement, Thermodynamics Modeling and Process Simulation for Extraction of Phenols from Coal Chemical Wastewater with Methyl Propyl Ketone. Chemical Engineering Research and Design, 147, 587-596. https://doi.org/10.1016/j.cherd.2019.05.050

[14] Raza, W., Lee, J., Raza, N., Luo, Y., Kim, K.-H. and Yang, J. (2019) Removal of Phenolic Compounds from Industrial Waste Water Based on Membrane-Based Technologies. Journal of Industrial and Engineering Chemistry, 71, 1-18. https://doi.org/10.1016/j.jiec.2018.11.024

[15] Ren, L.-F., Al Yousif, E., Xia, F., Wang, Y., Guo, L., Tu, Y., Zhang, X., Shao, J. and He, Y. (2019) Novel Electrospun TPU/PDMS/PMMA Membrane for Phenol Separation from Saline Wastewater via Membrane Aromatic Recovery System. Separation and Purification Technology, 212, 21-29. https://doi.org/10.1016/j.seppur.2018.11.006

[16] Ahmed, S., Rasul, M.G., Martens, W.N., Brown, R. and Hashib, M.A. (2010) Heterogeneous Photocatalytic Degradation of Phenols in Wastewater: A Review on Current Status and Developments. Desalination, 261, 3-18.

https://doi.org/10.1016/j.desal.2010.04.062

[17] Samsudin, M.F.R., Bacho, N., Sufian, S. and Ng, Y.H. (2019) Photocatalytic Degradation of Phenol Wastewater over Z-Scheme g-C3N4/CNT/BiVO4 Heterostructure Photocatalyst under Solar Light Irradiation. Journal of Molecular Liquids, 277, 977-988. https://doi.org/10.1016/j.molliq.2018.10.160

[18] Noworyta, A., Trusek-Hołownia, A., Mielczarski, S. and Kubasiewicz-Ponitka, M. (2006) An Integrated Pervaporation-Biodegradation Process of Phenolic Wastewater Treatment. Desalination, 198, 191-197. https://doi.org/10.1016/j.desal.2006.01.025

[19] Wu, D., Chen, G.Q., Hu, B. and Deng, H. (2019) Feasibility and Energy Consumption Analysis of Phenol Removal from Salty Wastewater by Electro-Electrodialysis. Separation and Purification Technology, 215, 44-50.

https://doi.org/10.1016/j.seppur.2019.01.001

[20] Hamdaoui, O. and Naffrechoux, E. (2007) Modeling of Adsorption Isotherms of Phenol and Chlorophenols onto Granular Activated Carbon Part I. Two-Parameter Models and Equations Allowing Determination of Thermodynamic Parameters. Journal of Hazardous Materials, 147, 381-394. https://doi.org/10.1016/j.jhazmat.2007.01.021

[21] Singh, N.B., Nagpal, G., Agrawal, S. and Rachna. (2018) Water Purification by Using Adsorbents: A Review. Environmental Technology \& Innovation, 11, 187-240. https://doi.org/10.1016/j.eti.2018.05.006

[22] Ahmaruzzaman, M. and Sharma, D.K. (2005) Adsorption of Phenols from Wastewater. Journal of Colloid and Interface Science, 287, 14-24. https://doi.org/10.1016/j.jcis.2005.01.075

[23] Sulaymon, A.H. and Ahmed, K.W. (2008) Competitive Adsorption of Furfural and Phenolic Compounds onto Activated Carbon in Fixed Bed Column. Environmental Science \& Technology, 42, 392-397. https://doi.org/10.1021/es070516j

[24] Tang, X., Ripepi, N., Rigby, S., Mokaya, R. and Gilliland, E. (2019) New Perspectives on Supercritical Methane Adsorption in Shales and Associated Thermodynamics. Journal of Industrial and Engineering Chemistry, 78, 186-197. https://doi.org/10.1016/j.jiec.2019.06.015

[25] Guo, S., Lü, X., Song, X. and Liu, Y. (2017) Methane Adsorption Characteristics and Influence Factors of Mesozoic Shales in the Kuqa Depression, Tarim Basin, China. Journal of Petroleum Science and Engineering, 157, 187-195. https://doi.org/10.1016/j.petrol.2017.07.020 
[26] Sprynskyy, M., Gadzała-Kopciuch, R., Nowak, K. and Buszewski, B. (2012) Removal of Zearalenone Toxin from Synthetics Gastric and Body Fluids Using Talc and Diatomite: A Batch Kinetic Study. Colloids and Surfaces B: Biointerfaces, 94, 7-14. https://doi.org/10.1016/j.colsurfb.2011.12.024

[27] Yu, W., Xu, H., Tan, D., Fang, Y., Roden, E.E. and Wan, Q. (2020) Adsorption of Iodate on Nanosized Tubular Halloysite. Applied Clay Science, 184, Article ID: 105407. https://doi.org/10.1016/j.clay.2019.105407

[28] Bristow, T.F., Kennedy, M.J., Derkowski, A., Droser, M.L., Jiang, G. and Creaser, R.A. (2009) Mineralogical Constraints on the Paleoenvironments of the Ediacaran Doushantuo Formation. Proceedings of the National Academy of Sciences of the United States of America, 106, 13190-13195. https://doi.org/10.1073/pnas.0901080106

[29] Wang, Y.-F., Zhai, G.-Y., Lu, Y.-C., Ma, Y.-Q., Li, J. and Liu, G.-H. (2019) Sedimentary Lithofacies Characteristics and Sweet-Spot Interval Characterization of the Sinian Doushantuo Formation in Upper Yangtze Platform, South China. China Geology, 2, 259-273. https://doi.org/10.31035/cg2018119

[30] Nayak, P.S. and Singh, B.K. (2007) Removal of Phenol from Aqueous Solutions by Sorption on Low Cost Clay. Desalination, 207, 71-79. https://doi.org/10.1016/j.desal.2006.07.005

[31] Ding, K.-L., Li, S.-Y., Yue, C.-T. and Zhong, N.-N. (2007) Simulation Experiments on Thermochemical Sulfate Reduction Using Natural Gas. Journal of Fuel Chemistry and Technology, 35, 401-406. https://doi.org/10.1016/S1872-5813(07)60025-5

[32] Wieckowski, T. and Wiewiora, A. (1976) New Approach to the Problem of the Interlayer Bonding in Kaolinite. Clays and Clay Minerals, 24, 219-223. https://doi.org/10.1346/CCMN.1976.0240502

[33] Sing, K.S. (1985) Reporting Physisorption Data for Gas/Solid Systems with Special Reference to the Determination of Surface Area and Porosity (Recommendations 1984). Pure and Applied Chemistry, 57, 603-619. https://doi.org/10.1351/pac198557040603

[34] Wang, Q., Jiao, G., Liu, H., Bai, J. and Li, S. (2010) Variation of the Pore Structure during Microwave Pyrolysis of Oil Shale. Oil Shale, 27, 135-146. https://doi.org/10.3176/oil.2010.2.04

[35] Bhowmik, S. and Dutta, P. (2019) A Study on the Effect of Gas Shale Composition and Pore Structure on Methane Sorption. Journal of Natural Gas Science and Engineering, 62, 144-156. https://doi.org/10.1016/j.jngse.2018.12.009

[36] Cavelan, A., Boussafir, M., Rozenbaum, O. and Laggoun-Défarge, F. (2019) Organic Petrography and Pore Structure Characterization of Low-Mature and Gas-Mature Marine Organic-Rich Mudstones: Insights into Porosity Controls in Gas Shale Systems. Marine and Petroleum Geology, 103, 331-350. https://doi.org/10.1016/j.marpetgeo.2019.02.027

[37] García, J.E., González, M.M. and Notario, J.S. (1993) Phenol Adsorption on Natural Phillipsite. Reactive Polymers, 21, 171-176. https://doi.org/10.1016/0923-1137(93)90119-Z

[38] Wang, Y., Shen, Z., Niu, J. and Liu, R. (2009) Adsorption of Phosphorus on Sediments from the Three-Gorges Reservoir (China) and the Relation with Sediment Compositions. Journal of Hazardous Materials, 162, 92-98. https://doi.org/10.1016/j.jhazmat.2008.05.013

[39] Olgun, A. and Atar, N. (2012) Equilibrium, Thermodynamic and Kinetic Studies for the Adsorption of Lead(II) and Nickel(II) onto Clay Mixture Containing Boron 
Impurity. Journal of Industrial and Engineering Chemistry, 18, 1751-1757. https://doi.org/10.1016/j.jiec.2012.03.020

[40] Subramanyam, B. and Das, A. (2009) Study of the Adsorption of Phenol by Two Soils Based on Kinetic and Isotherm Modeling Analyses. Desalination, 249, 914-921. https://doi.org/10.1016/j.desal.2009.05.020

[41] Yousef, R.I., El-Eswed, B. and Al-Muhtaseb, A.H. (2011) Adsorption Characteristics of Natural Zeolites as Solid Adsorbents for Phenol Removal from Aqueous Solutions: Kinetics, Mechanism, and Thermodynamics Studies. Chemical Engineering Journal, 171, 1143-1149. https://doi.org/10.1016/j.cej.2011.05.012

[42] Chingombe, P., Saha, B. and Wakeman, R.J. (2006) Sorption of Atrazine on Conventional and Surface Modified Activated Carbons. Journal of Colloid and Interface Science, 302, 408-416. https://doi.org/10.1016/j.jcis.2006.06.065

[43] Ho, Y.S., Ng, J.C.Y. and McKay, G. (2001) Removal of Lead(II) from Effluents by Sorption on Peat Using Second-Order Kinetics. Separation Science and Technology, 36, 241-261. https://doi.org/10.1081/SS-100001077

[44] Limousin, G., Gaudet, J.P., Charlet, L., Szenknect, S., Barthès, V. and Krimissa, M. (2007) Sorption Isotherms: A Review on Physical Bases, Modeling and Measurement. Applied Geochemistry, 22, 249-275. https://doi.org/10.1016/j.apgeochem.2006.09.010

[45] Yousef, R.I. and El-Eswed, B. (2009) The Effect of pH on the Adsorption of Phenol and Chlorophenols onto Natural Zeolite. Colloids and Surfaces A, 334, 92-99. https://doi.org/10.1016/j.colsurfa.2008.10.004

[46] Wu, H., Lin, Y., Wu, J., Zeng, L., Zeng, D. and Du, J. (2008) Surface Adsorption of Iron Oxide Minerals for Phenol and Dissolved Organic Matter. Frontiers of Earth Science, 15, 133-141. https://doi.org/10.1016/S1872-5791(09)60013-0

[47] Pura, S. and Atun, G. (2005) Enhancement of Nitrophenol Adsorption in the Presence of Anionic Surfactant and the Effect of the Substituent Position. Colloids and Surfaces A, 253, 137-144. https://doi.org/10.1016/j.colsurfa.2004.11.004

[48] Laquer, F.C. and Manahan, S.E. (1987) Solution Factors Affecting the Adsorption of Phenol onto a Siltstone. Chemosphere, 16, 1431-1445. https://doi.org/10.1016/0045-6535(87)90083-X

[49] Hank, D., Azi, Z., Ait Hocine, S., Chaalal, O. and Hellal, A. (2014) Optimization of Phenol Adsorption onto Bentonite by Factorial Design Methodology. Journal of Industrial and Engineering Chemistry, 20, 2256-2263. https://doi.org/10.1016/j.jiec.2013.09.058

[50] Polat, H., Molva, M. and Polat, M. (2006) Capacity and Mechanism of Phenol Adsorption on Lignite. International Journal of Mineral Processing, 79, 264-273. https://doi.org/10.1016/j.minpro.2006.03.003

[51] Parshetti, G.K., Chowdhury, S. and Balasubramanian, R. (2014) Hydrothermal Conversion of Urban Food Waste to Chars for Removal of Textile Dyes from Contaminated Waters. Bioresource Technology, 161, 310-319. https://doi.org/10.1016/j.biortech.2014.03.087

[52] Wang, S., Hao, C., Wang, D., Dong, H. and Qiu, J. (2011) Hydrogen Bonding Dynamics of Phenol- $\left(\mathrm{H}_{2} \mathrm{O}\right)_{2}$ Cluster in the Electronic Excited State: A DFT/TDDFT Study. Korean Chemical Society, 55, 385. https://doi.org/10.5012/jkcs.2011.55.3.385

[53] Jain, A.K., Suhas and Bhatnagar, A. (2002) Methylphenols Removal from Water by Low-Cost Adsorbents. Journal of Colloid and Interface Science, 251, 39-45. https://doi.org/10.1006/jcis.2002.8395

[54] Banat, F., Albashir, B., Alasheh, S. and Hayajneh, O. (2000) Adsorption of Phenol 
by Bentonite. Environmental Pollution, 107, 391-398.

https://doi.org/10.1016/S0269-7491(99)00173-6

[55] Kaleta, J. (2006) Removal of Phenol from Aqueous Solution by Adsorption. Canadian Journal of Civil Engineering, 33, 546-551. https://doi.org/10.1139/106-018

[56] Taha, M.R., Leng, T.O., Mohamad, A.B. and Kadhum, A.A.H. (2003) Batch Adsorption Tests of Phenol in Soils. Bulletin of Engineering Geology and the Environment, 62, 251-257. https://doi.org/10.1007/s10064-002-0181-2

[57] Darwish, N.A., Halhouli, K.A. and Al-Dhoon, N.M. (1996) Adsorption of Phenol from Aqueous Systems onto Spent Oil Shale. Separation Science and Technology, 31, 705-714. https://doi.org/10.1080/01496399608000714

[58] Viraraghavan, T. and Alfaro, F.M. (1998) Adsorption of Phenol from Wastewater by Peat, Fly Ash and Bentonite. Journal of Hazardous Materials, 57, 59-70. https://doi.org/10.1016/S0304-3894(97)00062-9

[59] Lin, S.H., Hsiao, R.C. and Juang, R.S. (2006) Removal of Soluble Organics from Water by a Hybrid Process of Clay Adsorption and Membrane Filtration. Journal of Hazardous Materials, 135, 134-140. https://doi.org/10.1016/j.jhazmat.2005.11.030

[60] Ahsan, T., Wu, J.H. and Arnett, E.M. (1994) Effects of Citric Acid Washing on the Thermodynamic Interaction of Some Coals with Acids. Fuel, 73, 417-422. https://doi.org/10.1016/0016-2361(94)90096-5

[61] Busca, G., Berardinelli, S., Resini, C. and Arrighi, L. (2008) Technologies for the Removal of Phenol from Fluid Streams: A Short Review of Recent Developments. Journal of Hazardous Materials, 160, 265-288. https://doi.org/10.1016/j.jhazmat.2008.03.045

[62] Zhu, L., Chen, B. and Shen, X. (2000) Sorption of Phenol, p-Nitrophenol, and Aniline to Dual-Cation Organobentonites from Water. Environmental Science \& Technology, 34, 468-475. https://doi.org/10.1021/es990177x 